\title{
Chromatin regulators of neural development
}

Kelsey Tyssowski ${ }^{1 *}$, Yusuke Kishi ${ }^{1}$, and Yukiko Gotoh ${ }^{1, *}$

${ }^{1}$ Institute of Molecular and Cellular Biosciences, University of Tokyo, Tokyo, Japan.

*To whom correspondence should be addressed at Institute of Molecular and Cellular

Biosciences, University of Tokyo, 1-1-1 Yayoi, Bunkyo-ku, Tokyo 113-0032, Japan. Tel. 81-

3-5841-8473; Fax. 81-3-5841-8472; E-mail: ygotoh@iam.u-tokyo.ac.jp,

tyssowski@,fas.harvard.edu 


\begin{abstract}
During all stages of neural development — from the fate switches of neural precursor/progenitor cells (NPCs) to activity dependent synapse maturation-chromatin-level modifications are important regulators of the gene expression that controls developmental programs. Such modifications, including both alterations of histone tails and cytosine residues in the DNA, as well as changes in the chromatin structure, act dynamically throughout development and work together to determine the chromatin state at each time point. While many studies have shown localized action of chromatin modifiers at relevant gene loci, recent reports have also indicated that some chromatin modifications work on a more global scale, altering many loci throughout the genome. Here we review recent papers that describe the roles of chromatin-level regulation, at both the local and global scale, in the development of the mouse brain.
\end{abstract}

\title{
Keywords
}

Chromatin, neural development, neural precursor/progenitor cells, neuronal differentiation

\section{Abbreviations}

5hmC, 5-hydroxymethylcytosine; 5mC, 5-methylcytosine; BDNF, Brain-derived neurotrophic factor; CPN, callosal projection neuron; ctip2, (COUP-TF)-interacting protein 2; DNMT1, DNA methyltransferase 1; ESC, embryonic stem cell; gfap, glial fibrillary acidic protein; H3K27me3, histone $\mathrm{H} 3$ lysine 27 trimethylation HDAC, histone deacetylase; HSC, hematopoetic stem cell; HMGA, high mobility group AT-hook; Imp2/Igf2bp2, insulin-like growth factor 2 mRNA-binding protein 2; LINE1, long interspersed nucleotide element 1; $\mathrm{MeCP} 2$, methyl CpG binding protein 2; NCoR, nuclear receptor co-repressor; neurog1, neurogenin1; NF1A, nuclear factor $1 \mathrm{~A}$; NPC, neural precursor/progenitor cell; NuRD, nucleosome remodeling and histone deacetylase; PcG, Polycomb group; PRC, Polycomb Repressive Complex; RTT, Rett syndrome; SATB, special AT-rich sequence binding; SCPN, subcerebral projection neuron; STAT, Signal Transducer and Activator of Transcription; TET, ten-eleven translocation; TSS, transcription start site

\section{Introduction}

Epigenetic information transmitted through cell divisions to orchestrate developmental programs is often encoded by chromatin-level modifications. These modifications include those on the DNA, including methylation and hydroxymehtylation of 
cytosine residues, as well as alteration of histone tails and chromatin structure. While there are many types of histone modifications, which each have differing roles in regulating gene expression, we will focus here on Histone H3 lysine 27 trimethylation (H3K27me3), a repressive mark that is added by Polycomb group (PcG) proteins and removed by demethylases, and histone acetylation, a transcriptionally permissive mark, which is added by histone acetyltransferases (HATs) and removed by histone deacetylases (HDACs). DNA and histone modifications are recognized by readers, which recruit transcription factors or other chromatin-modifiers that can affect chromatin structure. Chromatin structure here refers to the higher order chromatin conformation, including chromatin looping and general condensation or opening of the chromatin. A decondensed chromatin structure allows transcription factors easier access to their targets and is generally associated with increased transcription, while a condensed chromatin structure has the opposite effect. Importantly, chromatin-modifiers, including those mediating DNA and histone modification, and regulators of the chromatin structure ultimately work together to determine the chromatin state at each point in development and to control the cell fate.

In the mammalian brain, accumulating evidence has proven that chromatin-level modifications play pivotal roles in coordinating developmental programs. Neural precursor/progenitor cells (NPCs) generate the various neuronal and glial subtypes in a precise order (Hirabayashi and Gotoh, 2005, Miller and Gauthier, 2007, Molyneaux et al., 2007). In the first steps of development, NPCs gradually lose their competence to produce neurons, sequentially making each neuronal subtype (in the neurogenic phase) and then producing glia (in the astrogenic phase) (Figure 1). These sequential fate switches, as well as the neuronal differentiation/maturation process, are heavily dependent on chromatin modifiers. A key issue to be considered is where such chromatin modifications occur in the genome. One possibility is localized regulation of the gene loci that are relevant to a certain developmental process - for example, specific repression of the neurogenic gene neurogenin 1 (neurog1) in NPCs upon their transition from the neurogenic to astrogenic phase (Hirabayashi et al., 2009). While there is a lot of evidence for this kind of regulation, recent studies have indicated that during neurodevelopmental processes, various types of modifications may be acting at many loci throughout the genome. Furthermore, it is possible that the already identified local modifications may be part of a genome-wide change in chromatin state. Therefore, this field is now in the process of investigating changes in DNA and histone modifications and chromatin structure on a genome-wide scale. Here we review recent studies from the past three years that provide insight about the chromatin-level 
regulation, at both the local and global scale, that is important for orchestrating neural development in mice.

\section{Ikaros}

During the neurogenic phase when NPCs generate the various neuronal subtypes (Figure 1), each cortical layer is produced sequentially, from deep layers to superficial layers (Molyneaux et al., 2007). Although a recent study showed that as early as embryonic day E10.5, some NPCs destined to generate Cux2+ superficial layer neurons are segregated from those generating deep layer neurons (Franco et al., 2012), clonal analyses showed that NPC clones labeled at E10-E13 can produce both deep and superficial layer neurons (Shen et al., 2006, Yu et al., 2009). No matter how heterogeneous NPCs are, data from birthdate analysis of neurons suggests that the timed switch from producing one cortical layer to the next is roughly synchronized among NPCs (Takahashi et al., 1999). Then, what regulates these timed switches of NPC fate? A recent study on Ikaros has hinted at the possibility that regulation of the chromatin state in NPCs may play a role in the production of deep layer neurons (Alsiö et al., 2013). In NPCs, Ikaros expression is highest at early stages, when deep layer neurons are produced, and overexpression of Ikaros increased the number of deep layer neurons, as identified by expression of deep layer markers including Ctip2, Tbr1 and Foxp2. While Ikaros is known to be a transcription factor, it has also been shown to localize at peri-centric herterochromatin, and in some contexts, play a role in condensing the chromatin state at target loci by facilitating heterochromatin formation and recruiting Nucleosome Remodeling and Histone Deacetylase (NuRD), a nucleosome remodeling complex that contains HDAC1 (Kim et al., 1999). On the other hand, Ikaros has also been suggested to activate transcription at some loci by recruiting the Switch/Sucrose Nonfermentable (SWI/SNF) chromatinremodeling complex (Kim et al., 1999). While it is possible that Ikaros's functions in altering the chromatin state acts in its role in promoting deep layer neuron production in NPCs, further studies are needed to clarify the role of chromatin structure in the neuronal subtype fate changes of NPCs. Furthermore, where Ikaros acts in the genome, whether at a few specific loci or globally, also remains to be determined. Interestingly, Ikaros in the mouse retina and its homolog, hunchback, in drosophila also contribute to early-fate neuronal production in precursor cells (Isshiki et al., 2001, Elliott et al., 2008), suggesting that this function may be conserved in various contexts. 


\section{DNA methylation}

In NPCs' neurogenic phase (Figure 1), the expression of astrocytic genes must be repressed. DNA methylation of cytosine residues ( 5 methylcytosine or $5 \mathrm{mC}$ ) is well studied as a mechanism for the suppression of astrocytic genes such as glial fibrillary acidic protein (gfap) (Takizawa et al., 2001, Fan et al., 2005, Namihira and Nakashima, 2013), but how DNA methylation itself is regulated is still a topic of investigation. In astrogenic NPCs, Signal Transducer and Activator of Transcription 3 (STAT3) of the Janus kinase-STAT (JAKSTAT) pathway activates gfap expression by binding to its promoter, but in neurogenic NPCs, methylation of the STAT-binding site blocks STAT3 binding (Bonni et al., 1997, Takizawa et al., 2001, He et al., 2005, Namihira and Nakashima, 2013). Furthermore, DNA methyltransferase 1 (DNMT1), seems to be at least partially responsible for maintaining this methylation during the neurogenic phase, suggesting that preventing DNMT1 from accessing the gfap promoter may result in the transition from the neurogenic to astrogenic phase (Fan et al., 2005). Interestingly, a recent study showed that Nuclear factor 1 A-type (NF1A), a Notchsignaling induced transcription factor that has previously been shown to potentiate NPC differentiation into astrocytes (Deneen et al., 2006), may sequester DNMT1 away from the gfap promoter (Namihira et al., 2009). Overexpression of NF1A reduced the binding of DNMT1 and the methylation at the gfap promoter, while it induced premature astrogeneisis. Furthermore, since the amount of DNA methylation at other astrocytic gene loci is also reduced during the transition from the neurogenic to astrocytic phase (Hatada et al., 2008), it is possible that NF1A acts on more than one locus to coordinate the timing of the expression of astrocytic genes, though further studies are needed to address this idea.

\section{Polycomb complex}

PcG proteins, which are generally mediators of gene repression, are important for both maintaining the undifferentiated state of NPCs and also for regulating their differentiation potential. The PcG proteins consist of two protein complexes, Polycomb Repressive complex 2 (PRC2), which contains the methyltransferase Ezh2 that is responsible for depositing the repressive $\mathrm{H} 3 \mathrm{~K} 27 \mathrm{me} 3$ mark, and PRC1, which recognizes H3K27me3 and contains a ubiquitin ligase, Ring1A or Ring1B, that is important for gene repression (Cao and Zhang, 2004, de Napoles et al., 2004, Schwartz and Pirrotta, 2007). Knockout of Ezh2 in the mouse neocortex at the onset of neurogenesis (E9.5) induces premature neurogenesis in place of self-renewal, resulting in exhaustion of NPCs by the late neurogenic phase and finally a thinner cortex compared to controls (Pereira et al., 2010). This is in accord with an earlier 
paper showing that acute knockdown of Bmi1, an essential component of PRC1, also results in defects in self-renewal as well as an increase in apoptosis in NPCs in vitro and in vivo (Fasano et al., 2007). These phenotypes are due to impaired repression of a cyclin-dependent kinase inhibitor, $p 21$, in the Bmi1 knockdown cells. Interestingly, constitutive knockout of Bmil does not affect the proliferative activity of embryonic NPCs (Molofsky et al., 2003), suggesting that complete loss of Bmil from the beginning of development may be compensated for by other mechanisms to allow for normal cortical development. In short, it appears that various PcG proteins are important for maintaining NPC self-renewal in the neurogenic phase.

After the neurogenic phase, NPCs transition to the astrogenic phase (Figure 1), at which point neurogenic genes must be repressed. Interestingly, $\mathrm{PcG}$ proteins are also important in this later stage of development, as they play a role in regulating the transition to the astrogenic phase by repressing neurogenic genes in non-neurogenic NPCs (Figure 2A). An earlier study showed that PcG proteins repress neurog1 and neurog2, key determinants of neuronal fate in the neocortex, as NPCs switch from the neurogenic to astrogenic phase (Hirabayashi et al., 2009). Therefore, PcG proteins appear to have distinct roles at multiple developmental stages during corticogenesis.

However, how PcG proteins are regulated is less well understood. Recently, ncRNA has been implicated in recruiting PcG complexes to target loci in embryonic stem cells (ESCs) (Brockdorff, 2013). In NPCs, neurogl expression is activated by the ncRNA utngn1, which is transcribed from an enhancer element of the neurogl locus (Onoguchi et al., 2012), raising the possibility that utngn 1 might negatively regulate $\mathrm{PcG}$ activity at this locus. Further studies are needed to determine the role of ncRNA in PcG targeting to other neurogenic gene loci in NPCs.

\section{HMGA}

Recently, high mobility group AT-hook (HMGA) proteins have emerged as important players in regulating the neurogenic potential and self-renewal capacity of NPCs (Nishino et al., 2008, Kishi et al., 2012). HMGA1 and HMGA2, members of the HMG subfamily, contain several AT-hook regions that bind preferentially to AT-rich stretches of B-form DNA (Reeves, 2001, Fusco and Fedele, 2007). They can be categorized as modifiers of chromatin structure, as they usually act to open the chromatin state. HMGA1 and HMGA2 are highly expressed during early development, and have been shown to play a regulatory role in various types of stem cells, including ESCs, hematopoetic stem cells (HSCs) and myoblasts 
(Li et al., 2012, Oguro et al., 2012, Shah et al., 2012). In NPCs, it has been suggested that HMGA proteins promote NPC self-renewal capacity, suppress astrocyte differentiation, and promote NPCs' neurogenic potential, generally promoting early-stage NPC characteristics (Nishino et al., 2008, Sanosaka et al., 2008, Kishi et al., 2012).

Interestingly, a recent report showed that double knockdown of HMGA1 and HMGA2 in NPCs resulted in the generation of fewer neurons and more astrocytes during the neurogenic phase (Kishi et al., 2012, Figure 2A). Furthermore, NPCs in which HGMA1 and HMGA2 were overexpressed in early stages could generate neurons even in the postnatal neocortex, suggesting that HMGA overexpression can elongate the neurogenic phase. Interestingly, expression of HMGA proteins can also revive the neuron production of postnatal NPCs, returning them to a more early-stage state. Namely, when HMGA1 and HMGA2 were overexpressed in the postnatal brain, postnatal NPCs, which usually do not generate neurons, regained their neurogenic potential.

This finding raises the question of how HMGA proteins regulate the neurogenic potential of NPCs. One possible mechanism is alteration of the global chromatin structure (Kishi et al, 2012) (Figure 2B). When HMGA expression is high (i.e. the neurogenic phase), the global chromatin structure is less condensed than when HMGA expression in lower (i.e. the astrogenic phase), and furthermore, HMGA overexpression in later stages results in a more open chromatin state similar to that of early-stage NPCs. Importantly, expression of a mutant linker histone $\mathrm{H} 1$ that has an increased affinity for chromatin (and thus should condense the chromatin state) canceled the HMGA overexpression-induced increase in neurogenesis. Therefore, it seems that the HMGA-mediated global opening of the chromatin state in early-stage NPCs plays an important role in their neurogenic potential.

The possibility that the openness of the chromatin structure plays a role in the early stage characteristics and neurogenic potential of NPCs is supported by recent studies showing that genome-wide regulation of the chromatin structure also changes over differentiation during ESC differentiation into the neuronal lineage and establishment of primordial germ cell pluripotency (Meshorer et al., 2006, Hajkova et al., 2008, Figure 2B). In ESCs, architectural proteins, such as heterochromatin protein 1 (HP1) and linker histone H1, are more dynamic than in differentiated NPCs. Furthermore, in ESCs, knockdown of Chromodomain-helicase-DNA-binding protein 1 (Chd1), which results in limited H1 exchange rate, increases the number of differentiated cells produced, suggesting that dynamic, open chromatin may be associated with more stem-like cells (Gaspar-Maia et al., 2009). Furthermore, transcription levels in ESCs decrease during their differentiation, 
indicating that the open chromatin state may contribute to pluripotency by allowing a global increase in transcription of the genome (Efroni et al., 2008). This supports the model in which a globally open chromatin state in ESCs, which is regulated in part by Chd1, allows for the transcription of many genes that are expressed in ESCs as well as those in lineagecommitted cells. In this model, specific transcription factors would be responsible for expressing the genes necessary for ESC maintenance. As the chromatin condenses when ESCs differentiate, both genes that maintain ESCs in their undifferentiated state and some lineage-specific genes can no longer be expressed (Meshorer and Misteli, 2006). It is possible that a similar model exists in NPCs. The global opening of the chromatin state by HMGA proteins in early stages of NPC development would open both neurogenic and gliogenic loci, but transcription factors such as Neurog1 and Neurog2 would promote transcription of only neuronal genes, giving cells neurogenic potential. Then, during development, the loss of HMGA proteins might globally close the chromatin, reducing expression of neurogenic genes so that the cells lose their neurogenic potential. Further studies that clarify the specific regions opened by HMGA in the early stages and closed in the late stages might provide some insight into the significance of global chromatin condensation during NPC development.

In addition to its roles in global chromatin regulation, recent reports have also identified localized actions of HMGA proteins that are involved in its role in regulating the neurogenic potential. HMGA proteins can act as transcription factors by altering the chromatin state of specific loci and can also regulate the activity of other transcription factors (Fusco and Fedele, 2007). One of the genes known to be regulated by HMGA proteins is insulin-like growth factor binding protein 2 (imp2/igfbp2), which codes for an RNA-binding protein that regulates the subcellular localization, translation, and stability of mRNA (Christiansen et al., 2009). Imp2 is upregulated upon HMGA overexpression, and, as with HMGA, overexpression of Imp2 increases the neurogenic potential of NPCs, while knockdown has the opposite effect (Fujii et al., 2013). While Imp2 has been implicated in the growth of glioblastomas, its role in the normal central nervous system is relatively unknown (Janiszewska et al., 2012). Interestingly, overexpression of Imp2 can partially rescue the reduction of NPCs' neurogenic potential caused by HMGA knockdown (Fujii, Y. and YG, unpublished data), suggesting that HMGA might act through Imp2 to regulate neurogenic potential. The HMGA-Imp2 pathway has also recently been shown to contribute to the undifferentiated state of myoblasts and cancer cells (Li et al., 2012, Li et al., 2013), raising 
the possibility that this pathway might be generally important for stemness in various systems.

Then, what regulates HMGA proteins? Interestingly, in various cell types both HMGA1 and HMGA2 have been shown to be regulated by Myc, one of the four factors originally found to trigger the reprogramming of somatic cells into pluripotent cells (Takahashi and Yamanaka, 2006, Takahashi et al., 2007). It was shown in a mouse fibroblast cell line that Myc induces the transcription of hmgal by directly binding to the E-box element in the promoter region (Wood et al., 2000). As for HMGA2, Myc acts through Lin28, another reprogramming factor, to stabilize hmga $2 \mathrm{mRNA}$. In a human B-cell line, Myc was shown to upregulate the expression of lin28b (Chang et al., 2009). Importantly, in several cell lines, including P19 and 293T, and in endogenous hematopoietic stem cells, lin28b has been shown to represses let-7, a microRNA that degrades $h m g a 2$ mRNA (Heo et al., 2008, Newman et al., 2008, Piskounova et al., 2008, Rybak et al., 2008, Viswanathan et al., 2008, Copley et al., 2013). Since Lin28b and Myc are regulators of the neurogenic potential in NPCs (Nagao et al., 2008, Balzer et al., 2010), it is possible that the Myc-HMGA pathway is also active during central nervous system development (Figure 2A). Furthermore, both HMGA1 and HMGA2 have been shown to promote the expression of Myc (Li et al., 2012, Shah et al., 2012), suggesting that there is positive feedback between HMGA and Myc. Since HMGA proteins contribute to the pluripotent state of ES cells (Shah et al., 2012), MycHMGA positive feedback could be a general "reprogramming feedback" in many cell types, inducing differentiation in ESCs and reduction of the neurogenic potential in NPCs. The finding that HMGA proteins can reprogram astrogenic NPCs to neurogenic NPCs in vivo is consistent with this idea.

The PcG complex has also been suggested to negatively regulate HMGA proteins (Figure 2A). In HSCs, HMGA is important for regulating the differentiation potential (Oguro et al., 2012). Interestingly, knockout of Bmi1, a component of PRC1 that regulates selfrenewal in NPCs, induces upregulation of $h m g a 2$ gene expression. This suggests that hmga 2 repression by PcG might be important in regulation of self-renewal and differentiation in HSCs. In our preliminary results, we also found that PcG represses HMGA in NPCs: H3K27me3 can be found, and increases during development, at the HGMA2 gene locus, and Ring1B knockout activates HMGA2 gene expression (Hirabayashi, Y. and YG, unpublished data). Therefore, the PcG-HMGA pathway may regulate the differentiation and self-renewal potentials of many cell types through regulation of the chromatin state. 


\section{DNA 5-hydroxymethylcytosine}

The DNA modification 5-hydroxymethylcytosine $(5 \mathrm{hmC})$, which is found throughout the genome, is more abundant in the brain than in other tissues and has been suggested to play a role in neurodevelopmental processes. Unlike 5-methylcytosine $(5 \mathrm{mC})$, which is usually found in heterochromatin, $5 \mathrm{hmC}$ is associated with euochromatin and regions permissive of transcription in both neurons and ESCs (Ficz et al., 2011, Mellén et al., 2012, Hahn et al., 2013).

A recent study found that in neurons and NPCs, $5 \mathrm{hmC}$ is enriched in genes expressed in the brain, and furthermore, that $5 \mathrm{hmC}$ levels at such genes increase during early differentiation (Hahn et al., 2013). Whole nucleus $5 \mathrm{hmC}$ levels, as revealed by immunostaining, are low in the ventricular zone and the intermediate zone, which mostly consist of NPCs and intermediate progenitors, but comparatively higher in the cortical plate (at E15.5) and the mantle zone of ganglionic eminences (at E13.5), where differentiated neurons reside (Figure 3A). This trend was confirmed by comparison of NPCs to neurons using 5hmC DNA immunoprecipitation (DIP) and liquid chromatography tandem mass spectrometry (LC-MS/MS) quantification of cytosine modifications. Interestingly, unlike $5 \mathrm{hmC}$ found in ESCs, which is enriched in promoter regions (Ficz et al., 2011), throughout neural development, brain $5 \mathrm{hmC}$ is enriched in intragenic regions and not found at the transcription start site (TSS), but rather at the promoter region in early stages and just before the TSS in later stages (Szulwach et al., 2011, Mellén et al., 2012, Hahn et al., 2013). Comparing NPCs to neurons, it appears that the increase of $5 \mathrm{hmC}$ during early differentiation occurs in intragenic regions and that such intragenic accumulation is associated with higher transcriptional activity and is more common in genes important for functions including neuronal differentiation, migration, and axon guidance compared to other gene functions (Hahn et al., 2013).

Then, do $5 \mathrm{hmC}$ levels actually affect differentiation programs? $5 \mathrm{hmC}$ is added by Ten-eleven translocation (TET) protein-mediated conversion of existing $5 \mathrm{mC}$ to $5 \mathrm{hmC}$ (Cimmino et al., 2011). TET2/3 are the most highly expressed TET proteins in the cortex, and their expression increases during development, suggesting that they may mediate the observed increase in 5hmC (Hahn et al., 2013). Interestingly, overexpression of TET2 and TET3 in NPCs lead to fewer cells in the ventricular zone in exchange for a greater number of cells in the intermediate zone, which suggests an increase in differentiation and/or migration. Furthermore, brains in which both TET2 and TET3 were knocked down showed cell clusters along the radial axis, suggesting that the cells could not complete the differentiation program 
and migrate to the correct location (Hahn et al., 2013). Although it was not confirmed that TET2/3 overexpression and knockdown altered $5 \mathrm{hmC}$ levels, it appears that the conversion of $5 \mathrm{mC}$ to $5 \mathrm{hmC}$ is important for the completion of neuronal fate commitment and migration out of the ventricular zone.

Accumulation of $5 \mathrm{hmC}$ at the intragenic regions of neuronal genes was also found in later stages of development (Figure 3A): between postnatal day 7 (P7) and 1 year. Immunostaining of $5 \mathrm{hmC}$ in the hippocampus and cerebellum revealed that $5 \mathrm{hmC}$ increases between P7 and 6 weeks in both regions, and also between 6 weeks and one year in the cerebellum (Szulwach et al., 2011). However, no changes in the levels of TET proteins were found during this stage, suggesting other factors, such as alteration of the activity of TET proteins, regulate $5 \mathrm{hm}$ levels at this stage. Similar to the findings in earlier development, intragenic accumulation of $5 \mathrm{hmC}$ at these later stages was associated with genes that became actively transcribed between 6 weeks and P7 and was enriched in genes involved in neural development and neuronal functions, such as synaptic transmission. Furthermore, $5 \mathrm{hmC}$ profiles were found to vary between different cerebellar cell types (Mellén et al., 2012), as well as between adult neurons in different brain areas, with $5 \mathrm{hmC}$ specifically enriched in genes important for the areal functions (e.g. En2 in the cerebellum) (Szulwach et al., 2011). Thus, it is possible that $5 \mathrm{hmC}$ is responsible for the development of some cell-type specific characteristics. With the previously described study about $5 \mathrm{hmC}$ accumulation at earlier stages (Hahn et al., 2013), this hints at a model in which intragenic $5 \mathrm{hmC}$ is accumulated in a stage-dependent manner: in early stages at genes important for differentiation and migration, in later stages at those important for later-developed neuronal characteristics (e.g. synaptic transmission), and at the stage of subtype specification, which is dependent on the subtype, at subtype-specific loci. It is possible that such $5 \mathrm{hmC}$ accumulation is important for opening the chromatin state at these regions to allow for gene expression. However, it is important to note that $5 \mathrm{hmC}$ accumulation has not yet been causally linked to open chromatin or increased transcription and thus could be an effect rather than a cause of increased gene expression.

As previously mentioned, in addition to intragenic regions, $5 \mathrm{hmC}$ is also enriched in or around the promoter/TSS regions in the brain at both developmental time points investigated. While $5 \mathrm{hmC}$ in intragenic regions is associated with increased transcription, $5 \mathrm{hmC}$ accumulation at the promoter or TSS is found in early stages at genes that are not transcribed (Szulwach et al., 2011, Hahn et al., 2013). Because 5hmC is usually associated with transcribed genes and since this correlation between promoter/TSS $5 \mathrm{hmC}$ accumulation and low expression is seen only in early stages and, it is possible that $5 \mathrm{hmC}$ marks genes that 
are transcriptionally inactive but poised for activation (Szulwach et al., 2011), as is seen in ESCs (Cimmino et al., 2011). There is also evidence that at least some promoter $5 \mathrm{hmC}$ might play a role in activating genes in response to neuronal activity (Guo et al., 2011, Kaas et al., 2013, Rudenko et al., 2013). Recent studies using adult mice suggest that in response to neuronal activity, TET 1 mediates the loss of $5 \mathrm{mC}$, and increase of $5 \mathrm{hmC}$, at the promoters of activity-induced genes, as well as the increased expression of such genes. However, further work is needed to determine the role of $5 \mathrm{hmC}$ in this process (whether it is an intermediate of cytosine demethylation or if it has its own function) and if similar mechanisms are at work in neurodevelopmental programs. In short, $5 \mathrm{hmC}$ accumulation at both intragenic regions and the promoter/TSS may be important for expression of developmentally-relevant genes during both early and late-stage neural development.

A question that remains to be addressed is how $5 \mathrm{hmC}$ might affect gene expression and developmental programs. One possibility is through $5 \mathrm{hmC}$ readers. A recent study used mass spectrometry to identify several potential $5 \mathrm{hmC}$ readers found in NPCs differentiated from mouse ESCs and in the adult mouse brain (Spruijt et al., 2013). To this end, they incubated nuclear extracts from each cell type with DNA probes containing the $5 \mathrm{hmC}$ modification. Thus, further studies will be needed to confirm the function of these readers in vivo. That being said, in NPCs, the $5 \mathrm{hmC}$ readers identified include the $\mathrm{E} 3$ ubiquitin ligase, Ubiquitin-Like With PHD And Ring Finger Domains 2 (Uhrf2), which was found to promote TET1-mediated 5mC hydroxylation, and transcriptional repressors Zinc Fingers And Homeoboxes $1 / 2(\mathrm{Zhx} 1 / 2)$. In the adult brain, $5 \mathrm{hmC}$ readers include Ronin, which binds to transcriptional regulator Host cell factor 1(HCF-1) (Dejosez et al., 2008), and HMG family members HMG1/2 (or HMGB1/2), which, like HMGA1/2, are suggested to regulate chromatin structure (Reeves, 2010). Another recently identified 5hmC reader is Methyl CpG binding protein 2 (MeCP2), which we will discuss later (Mellén et al., 2012). The idea that there is a different subset of $5 \mathrm{hmC}$ readers in NPCs compared to neurons suggests that $5 \mathrm{hmC}$ may have different roles in these tissues. Furthermore, the finding that some readers bind $5 \mathrm{mC}$ but not $5 \mathrm{hmC}$, with the fact that that $5 \mathrm{mC}$ is converted into $5 \mathrm{hmC}$, suggests that part of $5 \mathrm{hmC}$ 's influence on gene expression might be due to a reduction in binding of $5 \mathrm{mC}$ readers. It has also been suggested that $5 \mathrm{hmC}$ and/or TET proteins may interact with PcG proteins (Wu et al., 2011, Hahn et al., 2013), though the mechanisms and causality of this interaction remain unclear. 


\section{SATB proteins}

While some evidence (see Ikaros section) suggests that at least some neuronal subtype specification occurs within NPCs, there is also evidence that chromatin regulation can play a role in specifying neuronal subtype in differentiated neurons. Special AT-rich sequence Binding (SATB) proteins, regulators of higher order chromatin structure, act in postmitotic neurons to influence subtype specification. In Th2 cells and tumorgenesis, SATB1 has been shown to mediate higher order chromatin structure by looping the chromatin (Cai et al., 2006, Kohwi-Shigematsu et al., 2013). Such looping is proposed to aid in recruitment of other chromatin-remodeling factors, such as SWI/SNF and NuRD, and to be necessary for parallel activation of genes contained in the looped chromatin. Another SATB family protein, SATB2, has $98 \%$ amino acid homology to SATB1 and has also been shown to recruit chromatinremodeling factors, including HDACs, though its role in chromatin looping has not been determined. In post-mitotic neurons, the chromatin looping mediated by SATB proteins has not been explicitly examined, but there is some evidence that SATB proteins regulate neuronal subtype specification by altering gene expression and/or the chromatin state.

SATB2 is involved in specifying the upper layer callosal projection neuron (CPN) fate over the subcerebral projection neuron (SCPN) fate by repressing the expression of (COUPTF)-interacting protein 2 (ctip2) (Alcamo et al., 2008, Britanova et al., 2008), a gene important for SCPN specification (Shoemaker and Arlotta, 2010). This repression results from direct binding of SATB2 to the ctip2 locus, recruitment of the HDAC1-containing NuRD complex, and subsequent deacetylation of histone H3 and H4. Importantly, SATB2 knockout neurons in vivo show axons that extend along the corticospinal tract, characteristic of SCPNs, instead of across the corpus callosum, as is characteristic of CPNs (Alcamo et al., 2008, Britanova et al., 2008). Furthermore, Ski, a protein previously shown to interact with HDAC1, was shown to recruit HDAC1 to the ctip2 locus and to be required for repression of ctip2 (Baranek et al., 2012). SATB2 positive neurons in Ski knockout mice showed failed axon projection across the corpus callosum similar to that observed in SATB2 knockouts, suggesting that without Ski, SATB2 positive neurons loose their CPN identity. Interestingly, Ski is recruited to the ctip2 locus by interacting directly with SATB2, and Ski is required for the formation of SATB2-HDAC1 complexes as well as the recruitment of HDAC1 to the ctip2 locus. These data suggest that the interaction between SATB2, Ski and HDAC1 decreases the transcriptional permissivity of the chromatin state at the ctip2 locus through histone deacetylation and leads to the subsequent ctip2 gene repression. Furthermore, as SATB2 is expressed in deep layer neurons in addition to CPNs, but Ski is expressed only in 
CPNs, it is possible that SATB2 may have a role in a variety of neuronal contexts and that Ski serves as an adaptor for the SATB2-mediated promotion of the CPN fate.

Furthermore, SATB1 was recently found to play a role in specifying a specific interneuron subtype, the somatostatin (SST)-expressing subtype, in post-mitotic MGEderived interneurons (Denaxa et al., 2012). A recent study showed that SATB1 expression is activated by neuronal activity in migrating, immature, LIM/homeobox protein 6 (Lhx6)expressing interneurons. Evidence from overexpression and knockout studies suggests that SATB1 acts downstream of interneuron-marker Lhx6 to alter the gene expression profile, migration, and differentiation of immature interneurons, thus committing them the SSTexpressing interneuron fate. It is unclear what the direct downstream targets of SATB1 are in this case, but it will be interesting to investigate their identity and how SATB1's chromatin looping function and recruitment of chromatin-remodeling factors plays a role in their expression.

\section{$\mathrm{MeCP2}$}

Methyl CpG binding protein 2 (MeCP2) is traditionally thought of as protein that binds methylated DNA in order to repress gene expression, but recent studies have shown it has a much more global, and less defined, role in repression, activation, and fine-tuning of gene expression. $\mathrm{MeCP} 2$ is much more abundant in the brain compared to other tissues and has been shown regulate the expression of specific genes involved in neural development, including brain-derived neurotrophic factor $(b d n f)$. Mutation of MeCP2 in humans causes a neurodevelopmental disease known as Rett syndrome (RTT), where children mature normally until 6-18 months of age, at which point symptoms appear (Guy et al., 2011). Furthermore, $\mathrm{MeCP} 2$ has been shown to play a role in shaping dendrite morphology and synapse formation (Na and Monteggia, 2011). Consistent with this idea, MeCP2 expression in mice is low before 5 weeks of age (Skene et al., 2010). This evidence supports the idea that MeCP2 acts in the late stages of post-mitotic neuronal development. However, it is also possible that $\mathrm{MeCP} 2$ is important for the maintenance, rather than the development of synapses, and it is difficult to distinguish between these possibilities. Furthermore, the roles of MeCP2 in other cell types, such as astrocytes and microglia, have also been implicated in RTT pathogenesis, although we will not discuss the cell type specific functions of MeCP2 in this review. While RTT and MeCP2 knockout studies make it clear that MeCP2 is important for the formation and/or maintenance of neuronal connections during development, how MeCP2 influences such structure on a molecular and gene-expression level is still a topic of much investigation. 
Recent studies have shown that MeCP2 does not merely regulate the expression of specific genes important for neural development, but rather alters the global chromatin state of postmitotic neurons.

Recent chromatin immunoprecipitation-sequencing (ChIP-seq) studies showed that MeCP2 binds globally in 6-8 week old neurons: it tracks methylated DNA uniformly throughout the genome without any obvious peaks of increased binding (Skene et al., 2010, Cohen et al., 2011). In fact, analysis of the levels of MeCP2 in neurons shows that it is about half as abundant as nucleosomes and that this abundance is specific to neurons and not seen in glia or other cell types (Skene et al., 2010, Cohen et al., 2011). Because MeCP2 has been shown to compete with histone H1 in binding to methylated DNA in vitro (Nan et al., 1997) and in cell culture (Ghosh et al., 2010), and since MeCP2 knockout neurons show 2x as much histone H1 compared to wild type neurons (Skene et al., 2010), it is possible that in neurons, one of two histone $\mathrm{H} 1$ molecules is replaced with MeCP2 (Figure 3B). This is consistent with the finding that neurons also have half as many $\mathrm{H} 1$ molecules as other cells (Pearson et al., 1984), but the functional implications of this potential replacement are unclear.

Then, how might such global binding affect the global chromatin state? Previous studies have suggested that $\mathrm{MeCP} 2$ recruits HDACs to specific gene loci (Figure 3B), thus proposing histone deacytelation as a mechanism for target gene repression $(\mathrm{Na}$ and Monteggia, 2011). Indeed, the repression of a reporter gene by MeCP2's N-terminal domain can be blocked by HDAC inhibitors (Lyst et al., 2013). Taking this idea to a global level, a recent study showed that $\mathrm{MeCP} 2$ knockout caused a global increase in histone $\mathrm{H} 3$ acetylation when measured at 6 weeks (Skene et al., 2010), a time point in mouse development relevant to RTT syndrome onset in humans. This suggests that $\mathrm{MeCP} 2$ globally reduces permissive histone marks during late development. $\mathrm{MeCP} 2$ has also been shown to interact with the HDAC-containing Nuclear receptor Corepressor (NCoR) complex (Ebert et al., 2013, Lyst et al., 2013). Thus, MeCP2's recruitment of NCoR could play a role in its reduction of histone acetylation. Importantly, one common RTT mutant inhibits the interaction between MeCP2 and NCoR (Lyst et al., 2013), suggesting that the interaction with this co-repressor is important for MeCP2's developmental functions.

Presenting another mechanism by which MeCP2 affects the chromatin state, another study found that MeCP2 may be able to alter the chromatin structure, as it contains multiple AT-hook domains (Baker et al., 2013). Interestingly, there are several cases of truncating RTT mutations that delete one or more of these AT-hook regions, and deletion of these regions in mice caused neurodevelopmental symptoms, limited MeCP2's ability to oligomerize 
nucleosomal arrays (NAs), and disrupted the localization of the chromatin remodeling protein a-thalassemia/mental retardation syndrome X linked (ATRX). Thus, it seems that both $\mathrm{MeCP} 2$ 's facilitation of histone modification and its ability to alter chromatin structure are important in its developmental roles.

This raises the question of how the chromatin changes orchestrated by MeCP2 are linked to its roles in development. As many of the proposed developmental roles of MeCP2, including regulating synapse development and dendrite arborization, occur in response to neuronal activity, it would make sense if the depolarization-induced phosphorylation of $\mathrm{MeCP} 2$ were able to alter its role in chromatin and/or transcriptional regulation. Phosphorylation of MeCP2 at several sites occurs in response to environmental cues, including membrane depolarization (Chen et al., 2003, Zhou et al., 2006, Cohen et al., 2011, Li et al., 2011, Ebert et al., 2013), BDNF and forskolin induction of protein kinase A (Ebert et al., 2013). Furthermore, it seems that MeCP2 might be a convergence point for various signaling pathways, as each pathway favors different phosphorylation sites (Ebert et al., 2013), though it is unclear how such differential phosphorylation affects MeCP2's role in chromatin state or transcriptional regulation.

In vitro studies found that neuronal-activity induced phosphorylation of $\mathrm{MeCP} 2$ induces its removal from the $b d n f$ promoter and subsequent expression of $b d n f$ (Chen et al., 2003, Zhou et al., 2006). This was recently partially confirmed in vivo in the adult mouse hippocampus (Li et al., 2011). Mice with knock-in of a 2-site phosphorylation-deficient mutant (MeCP2 S421A S424A) showed increased MeCP2 occupancy at several genes, including $b d n f$, compared to wild type mice, and while gene expression at the differentially occupied loci was different between knock-in mice and controls, it was neither consistently higher nor lower in knock-ins. In fact, contrary to in vitro studies, bdnf expression was higher in MeCP2 S421A/S424A than in controls. This supports a model in which MeCP2 binding to promoters can either activate or repress gene expression (as previously suggested: (Chahrour et al., 2008, Ben-Shachar et al., 2009)), and phosphorylation of MeCP2 reduces such binding. In this model, changes in the binding patterns of $\mathrm{MeCP} 2$ upon neuronal-activity induced phosphorylation could change the localization of MeCP2's partners or alter the chromatin structure of MeCP2-bound regions (Figure 3C).

On the other hand, another recent in vivo study contradicts this model, suggesting that in the 6-8 week old mouse cortex, MeCP2 localization does not change following membrane depolarization. They also show that, upon neuronal activity, MeCP2 is phosphorylated at S421 evenly throughout the genome, and that 1-site phosphorylation-deficient (S421A) 
knock-in mice show no significant changes in gene expression both in microarray data and in RT-qPCR analysis of activity related genes, including $b d n f$ and $c$-fos. (Cohen, Neuron, 2011). However, they found that S421A knock-in mice showed increased dendrite branching and lower miniature inhibitory postsynaptic currents (mIPSCs). Therefore, it seems that phosphorylation of MeCP2 at S421 is at least partly responsible for some of MeCP2's developmental roles. Whether these phenotypic differences in MeCP2 S421A mice are due to a change in gene expression is unclear, but it is possible that the lack of phosphorylation at S421 caused small changes, or "fine-tuning", in gene expression, perhaps through genomewide alteration of the chromatin state, that were unable to be detected by microarray and were at loci not checked by RT-qPCR. On the other hand, investigation of a different phosphorylation site, T308A, revealed more robust phosphorylation-dependent gene expression differences (Ebert et al., 2013). Cultured cortical neurons from phosphorylationdeficient T308A knock-in mice compared to wild type neurons showed impaired induction of npas 4 and bdnf upon membrane depolarization, and this difference was also seen in the visual cortex in vivo when wild type and T308A knock-in dark-reared mice were exposed to light. Importantly, such phosyphorylation appears to be important for MeCP2's developmental roles, as MeCP2 T308A mice show mild RTT-like phenotypes. Furthermore, phosphorylation of T308A blocks MeCP2's interaction with NCoR and inhibits MeCP2-NCoR mediated gene repression. It is therefore possible that $\mathrm{MeCP} 2$ remains bound to the genome even upon phosphorylation, and phosyphorylation instead interferes with the interaction between $\mathrm{MeCP} 2$ and $\mathrm{NCoR}$, thereby leading to phosphorylation-induced activation of gene expression (Figure 3C). As previous studies have suggested that $\mathrm{MeCP} 2$ can either activate or repress genes, further work is needed to determine if and how MeCP2 phosphorylation might lead to gene repression in this model, though it is possible that it works with other partners in such regulation.

Another possible mechanism by which $\mathrm{MeCP} 2$ regulates neurodevelopmental processes is through regulation of long interspersed nucleotide element 1 (LINE1) retrotransposition. MeCP2 knockout NPCs and NPCs derived from RTT patients showed an increase of LINE1 retrotransposition (Muotri et al., 2010). Recently, retrotransposition of LINE1, one of the most abundant retrotransposons in the mammalian genome, has been suggested to occur frequently in neurons and to contribute to neuronal mosaicism (Muotri et al., 2005, Muotri and Gage, 2006), though this hypothesis is still controversial (Evrony et al., 2012). Interestingly, at 6-8 weeks of age, MeCP2 knockout neurons show higher levels of $5 \mathrm{hmC}$ at the LINE1 promoter compared to wild type neurons, raising the possibility that 
MeCP2 knockout results in increased activation of the LINE1 promoter due to a more open chromatin state caused by increased $5 \mathrm{hmC}$ (Szulwach et al., 2011).

As briefly mentioned above, recent studies have investigated the relationship between $\mathrm{MeCP} 2$ and $5 \mathrm{hmc}$, though it is unclear if $5 \mathrm{hmC}$ recruits $\mathrm{MeCP} 2$, if $\mathrm{MeCP} 2$ regulates $5 \mathrm{hmC}$ levels, or if there is feedback between them. One study in mature brains showed that MeCP2 binds not only 5mC, but also 5hmC (Mellén et al., 2012). Furthermore, knockout of MeCP2 caused $5 \mathrm{hmC}$-enriched regions to become less accessible to nuclease, suggesting that $\mathrm{MeCP} 2$ binding to $5 \mathrm{hmC}$ results in a more open chromatin structure. This raises the possibility of a model whereby $\mathrm{MeCP} 2$ binding to $5 \mathrm{hmC}$ activates gene expression by opening the chromatin, whereas binding to $5 \mathrm{mC}$ downregulates gene expression by condensing the chromatin. This model hints at a possible mechanism by which $5 \mathrm{hmC}$ could influence gene expression. Interestingly, there are RTT mutations of $\mathrm{MeCP} 2$ that can bind to $5 \mathrm{mC}$, but not to $5 \mathrm{hmC}$, suggesting that MeCP2's 5hmC binding is important for neural development (Mellén et al., 2012). It would be interesting to use such mutants to determine differences in activityinduced phosphorylation, gene expression regulation and binding patterns between $\mathrm{MeCP} 2$ bound to $5 \mathrm{mC}$ and that bound to $5 \mathrm{hmC}$.

On the other hand, there is also evidence that $\mathrm{MeCP} 2$ can regulate $5 \mathrm{hmC}$ levels, as observed at the LINE1 locus. In the cerebellum, global 5hmC levels at 6-8 weeks were negatively correlated with MeCP2 dosage (Szulwach et al., 2011), though this was not observed in adult neurons (Mellén et al., 2012). Interestingly, the methyl-binding domain of $\mathrm{MeCP} 2$ was shown to protect $5 \mathrm{mC}$ from TET-mediated conversion to $5 \mathrm{hmC}$ in vitro, suggesting that $\mathrm{MeCP} 2$ can regulate $5 \mathrm{hmC}$ levels by binding to $5 \mathrm{mC}$. In contrast, in adulthood, MeCP2 knockout resulted in a slight decrease in $5 \mathrm{hmC}$ only at expressed loci (Mellén et al., 2012), and at 6-8 weeks, 5hmC was lower in MeCP2 knockout neurons compared to controls specifically at loci that normally lose $5 \mathrm{hmC}$ between 6 weeks and 1 year (Szulwach et al., 2011). This suggests the possibility that MeCP2 plays a role in maintaining a base level of $5 \mathrm{hmC}$ in gene regions that lose $5 \mathrm{hmC}$ during late neurodevelopment. In short, it seems that $\mathrm{MeCP} 2$ could either play a role in regulation of $5 \mathrm{hmC}$ levels, be a reader of $5 \mathrm{hmC}$, with its binding patterns partly determined by $5 \mathrm{hmC}$ patterns, or both. Furthermore, the differences between 5hmC levels in MeCP2 knockout studies suggest that MeCP2's interaction with $5 \mathrm{hmC}$ could vary between brain areas or developmental stages. 


\section{Conclusions}

Recent studies have highlighted the role of chromatin modifiers such as DNMT, TET, HDAC, PcG, HMGA, MeCP2 and SATB proteins in various processes during neural development. It is likely that these modifiers do not act alone, but instead work together in different combinations to differentially regulate the chromatin state at various loci and developmental time points. Furthermore, it is clear that many of these modifiers, most notably HMGA, TET and MeCP2, act at many loci throughout the genome, considering that they are highly abundant. It is important to note that it is difficult to determine the significance of such "global" effects, since conventional gain or loss of function studies cannot distinguish the global effects of a molecule from its local effects. However, future genome-wide analysis will be useful for addressing the significance of local effects, as well as for putting them into a global context. Global investigation will clarify how chromatinregulators alter the chromatin state and gene expression at loci relevant to each step of development by allowing for the simultaneous investigation of the groups of specific loci known to be important for each step. This could elucidate, for instance, whether the genomic loci responsible for neuronal fate commitment are regulated together in a similar way but in a manner different from the loci responsible for activity dependent maturation. Sequencedirected targeting of a specific molecule (by TALE etc.) will also help to determine whether the resultant phenotypes of genome-wide changes in chromatin regulator binding/position are due to local and/or global actions (Zhang et al., 2011, Joung and Sander, 2013, Konermann et al., 2013). One possibility is that some genome-wide changes in chromatin regulators are the result of coordinated local changes at many specific loci. On the other hand, it is also possible that alteration of the global chromatin state itself, including changes in chromatin conformation, looping, clusters etc., is important in global gene regulation and that changes in specific gene expression are dependent on the global changes. Detailed analysis of genome-wide high-throughput sequencing data, as well as further investigation of higher order chromatin structure will provide insight into the significance of global chromatin changes and their role in coordinating gene expression patterns to trigger neurodevelopmental programs.

\section{Acknowledgements}

We apologize to all researchers whose work could not be cited owing to space limitation. Work in YG's lab is supported by a Grant-in-Aid for Scientific Research on Innovative Areas 
"Neural Diversity and Neocortical Organization" from the Ministry of Education, Culture, Sports, Science, and Technology (MEXT) of Japan and by CREST of the Japan Science and Technology Agency. 


\section{Reference}

Alcamo EA, Chirivella L, Dautzenberg M, Dobreva G, Fariñas I, Grosschedl R, McConnell SK (2008) Satb2 regulates callosal projection neuron identity in the developing cerebral cortex. Neuron 57:364-377.

Alsiö JM, Tarchini B, Cayouette M, Livesey FJ (2013) Ikaros promotes early-born neuronal fates in the cerebral cortex. Proc Natl Acad Sci U S A 110:E716-725.

Baker SA, Chen L, Wilkins AD, Yu P, Lichtarge O, Zoghbi HY (2013) An AT-hook domain in MeCP2 determines the clinical course of Rett syndrome and related disorders. Cell 152:984-996.

Balzer E, Heine C, Jiang Q, Lee VM, Moss EG (2010) LIN28 alters cell fate succession and acts independently of the let-7 microRNA during neurogliogenesis in vitro. Development 137:891-900.

Baranek C, Dittrich M, Parthasarathy S, Bonnon CG, Britanova O, Lanshakov D, Boukhtouche F, Sommer JE, Colmenares C, Tarabykin V, Atanasoski S (2012) Protooncogene Ski cooperates with the chromatin-remodeling factor Satb2 in specifying callosal neurons. Proc Natl Acad Sci U S A 109:3546-3551.

Ben-Shachar S, Chahrour M, Thaller C, Shaw CA, Zoghbi HY (2009) Mouse models of MeCP2 disorders share gene expression changes in the cerebellum and hypothalamus. Hum Mol Genet 18:2431-2442.

Bonni A, Sun Y, Nadal-Vicens M, Bhatt A, Frank DA, Rozovsky I, Stahl N, Yancopoulos GD, Greenberg ME (1997) Regulation of gliogenesis in the central nervous system by the JAK-STAT signaling pathway. Science 278:477-483.

Britanova O, de Juan Romero C, Cheung A, Kwan KY, Schwark M, Gyorgy A, Vogel T, Akopov S, Mitkovski M, Agoston D, Sestan N, Molnár Z, Tarabykin V (2008) Satb2 is a postmitotic determinant for upper-layer neuron specification in the neocortex. Neuron 57:378-392.

Brockdorff N (2013) Noncoding RNA and Polycomb recruitment. RNA 19:429-442.

Cai S, Lee CC, Kohwi-Shigematsu T (2006) SATB1 packages densely looped, transcriptionally active chromatin for coordinated expression of cytokine genes. Nat Genet 38:1278-1288.

Cao R, Zhang Y (2004) The functions of E(Z)/EZH2-mediated methylation of lysine 27 in histone H3. Curr Opin Genet Dev 14:155-164.

Chahrour M, Jung SY, Shaw C, Zhou X, Wong ST, Qin J, Zoghbi HY (2008) MeCP2, a key contributor to neurological disease, activates and represses transcription. Science 320:1224-1229.

Chang TC, Zeitels LR, Hwang HW, Chivukula RR, Wentzel EA, Dews M, Jung J, Gao P, Dang CV, Beer MA, Thomas-Tikhonenko A, Mendell JT (2009) Lin-28B transactivation is necessary for Myc-mediated let-7 repression and proliferation. Proc Natl Acad Sci U S A 106:3384-3389.

Chen WG, Chang Q, Lin Y, Meissner A, West AE, Griffith EC, Jaenisch R, Greenberg ME (2003) Derepression of BDNF transcription involves calcium-dependent phosphorylation of MeCP2. Science 302:885-889.

Christiansen J, Kolte AM, Hansen T, Nielsen FC (2009) IGF2 mRNA-binding protein 2: biological function and putative role in type 2 diabetes. J Mol Endocrinol 43:187195. 
Cimmino L, Abdel-Wahab 0, Levine RL, Aifantis I (2011) TET family proteins and their role in stem cell differentiation and transformation. Cell Stem Cell 9:193-204.

Cohen S, Gabel HW, Hemberg M, Hutchinson AN, Sadacca LA, Ebert DH, Harmin DA, Greenberg RS, Verdine VK, Zhou Z, Wetsel WC, West AE, Greenberg ME (2011) Genome-wide activity-dependent MeCP2 phosphorylation regulates nervous system development and function. Neuron 72:72-85.

Copley MR, Babovic S, Benz C, Knapp DJ, Beer PA, Kent DG, Wohrer S, Treloar DQ Day C, Rowe K, Mader H, Kuchenbauer F, Humphries RK, Eaves CJ (2013) The Lin28blet-7-Hmga2 axis determines the higher self-renewal potential of fetal haematopoietic stem cells. Nat Cell Biol 15:916-925.

de Napoles M, Mermoud JE, Wakao R, Tang YA, Endoh M, Appanah R, Nesterova TB, Silva J, Otte AP, Vidal M, Koseki H, Brockdorff N (2004) Polycomb group proteins Ring1A/B link ubiquitylation of histone $\mathrm{H} 2 \mathrm{~A}$ to heritable gene silencing and $\mathrm{X}$ inactivation. Dev Cell 7:663-676.

Dejosez M, Krumenacker JS, Zitur LJ, Passeri M, Chu LF, Songyang Z, Thomson JA, Zwaka TP (2008) Ronin is essential for embryogenesis and the pluripotency of mouse embryonic stem cells. Cell 133:1162-1174.

Denaxa M, Kalaitzidou M, Garefalaki A, Achimastou A, Lasrado R, Maes T, Pachnis V (2012) Maturation-promoting activity of SATB1 in MGE-derived cortical interneurons. Cell Rep 2:1351-1362.

Deneen B, Ho R, Lukaszewicz A, Hochstim CJ, Gronostajski RM, Anderson DJ (2006) The transcription factor NFIA controls the onset of gliogenesis in the developing spinal cord. Neuron 52:953-968.

Ebert DH, Gabel HW, Robinson ND, Kastan NR, Hu LS, Cohen S, Navarro AJ, Lyst MJ, Ekiert R, Bird AP, Greenberg ME (2013) Activity-dependent phosphorylation of MECP2 threonine 308 regulates interaction with NcoR. Nature.

Efroni S, Duttagupta R, Cheng J, Dehghani H, Hoeppner DJ, Dash C, Bazett-Jones DP, Le Grice S, McKay RD, Buetow KH, Gingeras TR, Misteli T, Meshorer E (2008) Global transcription in pluripotent embryonic stem cells. Cell Stem Cell 2:437-447.

Elliott J, Jolicoeur C, Ramamurthy V, Cayouette M (2008) Ikaros confers early temporal competence to mouse retinal progenitor cells. Neuron 60:26-39.

Evrony GD, Cai X, Lee E, Hills LB, Elhosary PC, Lehmann HS, Parker JJ, Atabay KD, Gilmore EC, Poduri A, Park PJ, Walsh CA (2012) Single-neuron sequencing analysis of L1 retrotransposition and somatic mutation in the human brain. Cell 151:483-496.

Fan G, Martinowich K, Chin MH, He F, Fouse SD, Hutnick L, Hattori D, Ge W, Shen Y, Wu H, ten Hoeve J, Shuai K, Sun YE (2005) DNA methylation controls the timing of astrogliogenesis through regulation of JAK-STAT signaling. Development 132:3345-3356.

Fasano CA, Dimos JT, Ivanova NB, Lowry N, Lemischka IR, Temple S (2007) shRNA knockdown of Bmi-1 reveals a critical role for $\mathrm{p} 21-\mathrm{Rb}$ pathway in NSC selfrenewal during development. Cell Stem Cell 1:87-99.

Ficz G, Branco MR, Seisenberger S, Santos F, Krueger F, Hore TA, Marques CJ, Andrews S, Reik W (2011) Dynamic regulation of 5-hydroxymethylcytosine in mouse ES cells and during differentiation. Nature 473:398-402.

Franco SJ, Gil-Sanz C, Martinez-Garay I, Espinosa A, Harkins-Perry SR, Ramos C, Müller U (2012) Fate-restricted neural progenitors in the mammalian cerebral cortex. Science 337:746-749. 
Fujii Y, Kishi Y, Gotoh Y (2013) IMP2 regulates differentiation potentials of mouse neocortical neural precursor cells. Genes Cells 18:79-89.

Fusco A, Fedele M (2007) Roles of HMGA proteins in cancer. Nat Rev Cancer 7:899-910.

Gaspar-Maia A, Alajem A, Polesso F, Sridharan R, Mason MJ, Heidersbach A, RamalhoSantos J, McManus MT, Plath K, Meshorer E, Ramalho-Santos M (2009) Chd1 regulates open chromatin and pluripotency of embryonic stem cells. Nature 460:863-868.

Ghosh RP, Horowitz-Scherer RA, Nikitina T, Shlyakhtenko LS, Woodcock CL (2010) MeCP2 binds cooperatively to its substrate and competes with histone $\mathrm{H} 1$ for chromatin binding sites. Mol Cell Biol 30:4656-4670.

Guo JU, Su Y, Zhong C, Ming GL, Song H (2011) Hydroxylation of 5-methylcytosine by TET1 promotes active DNA demethylation in the adult brain. Cell 145:423-434.

Guy J, Cheval H, Selfridge J, Bird A (2011) The role of MeCP2 in the brain. Annu Rev Cell Dev Biol 27:631-652.

Hahn MA, Qiu R, Wu X, Li AX, Zhang H, Wang J, Jui J, Jin SG, Jiang Y, Pfeifer GP, Lu Q (2013) Dynamics of 5-hydroxymethylcytosine and chromatin marks in Mammalian neurogenesis. Cell Rep 3:291-300.

Hajkova P, Ancelin K, Waldmann T, Lacoste N, Lange UC, Cesari F, Lee C, Almouzni G, Schneider R, Surani MA (2008) Chromatin dynamics during epigenetic reprogramming in the mouse germ line. Nature 452:877-881.

Hatada I, Namihira M, Morita S, Kimura M, Horii T, Nakashima K (2008) Astrocytespecific genes are generally demethylated in neural precursor cells prior to astrocytic differentiation. PLoS One 3:e3189.

He F, Ge W, Martinowich K, Becker-Catania S, Coskun V, Zhu W, Wu H, Castro D, Guillemot F, Fan G, de Vellis J, Sun YE (2005) A positive autoregulatory loop of Jak-STAT signaling controls the onset of astrogliogenesis. Nat Neurosci 8:616-625.

Heo I, Joo C, Cho J, Ha M, Han J, Kim VN (2008) Lin28 mediates the terminal uridylation of let-7 precursor MicroRNA. Mol Cell 32:276-284.

Hirabayashi Y, Gotoh Y (2005) Stage-dependent fate determination of neural precursor cells in mouse forebrain. Neurosci Res 51:331-336.

Hirabayashi Y, Suzki N, Tsuboi M, Endo TA, Toyoda T, Shinga J, Koseki H, Vidal M, Gotoh Y (2009) Polycomb limits the neurogenic competence of neural precursor cells to promote astrogenic fate transition. Neuron 63:600-613.

Isshiki T, Pearson B, Holbrook S, Doe CQ (2001) Drosophila neuroblasts sequentially express transcription factors which specify the temporal identity of their neuronal progeny. Cell 106:511-521.

Janiszewska M, Suvà ML, Riggi N, Houtkooper RH, Auwerx J, Clément-Schatlo V, Radovanovic I, Rheinbay E, Provero P, Stamenkovic I (2012) Imp2 controls oxidative phosphorylation and is crucial for preserving glioblastoma cancer stem cells. Genes Dev 26:1926-1944.

Joung JK, Sander JD (2013) TALENs: a widely applicable technology for targeted genome editing. Nat Rev Mol Cell Biol 14:49-55.

Kaas GA, Zhong C, Eason DE, Ross DL, Vachhani RV, Ming GL, King JR, Song H, Sweatt JD (2013) TET1 Controls CNS 5-Methylcytosine Hydroxylation, Active DNA Demethylation, Gene Transcription, and Memory Formation. Neuron 79:10861093.

Kim J, Sif S, Jones B, Jackson A, Koipally J, Heller E, Winandy S, Viel A, Sawyer A, Ikeda T, Kingston R, Georgopoulos K (1999) Ikaros DNA-binding proteins direct 
formation of chromatin remodeling complexes in lymphocytes. Immunity 10:345-355.

Kishi Y, Fujii Y, Hirabayashi Y, Gotoh Y (2012) HMGA regulates the global chromatin state and neurogenic potential in neocortical precursor cells. Nat Neurosci.

Kohwi-Shigematsu T, Poterlowicz K, Ordinario E, Han HJ, Botchkarev VA, Kohwi Y (2013) Genome organizing function of SATB1 in tumor progression. Semin Cancer Biol 23:72-79.

Konermann S, Brigham MD, Trevino AE, Hsu PD, Heidenreich M, Cong L, Platt RJ, Scott DA, Church GM, Zhang F (2013) Optical control of mammalian endogenous transcription and epigenetic states. Nature 500:472-476.

Li H, Zhong X, Chau KF, Williams EC, Chang Q (2011) Loss of activity-induced phosphorylation of MeCP2 enhances synaptogenesis, LTP and spatial memory. Nat Neurosci 14:1001-1008.

Li Z, Gilbert JA, Zhang Y, Zhang M, Qiu Q, Ramanujan K, Shavlakadze T, Eash JK, Scaramozza A, Goddeeris MM, Kirsch DG, Campbell KP, Brack AS, Glass DJ (2012) An HMGA2-IGF2BP2 axis regulates myoblast proliferation and myogenesis. Dev Cell 23:1176-1188.

Li Z, Zhang Y, Ramanujan K, Ma Y, Kirsch DG, Glass DJ (2013) Oncogenic NRAS, required for pathogenesis of embryonic rhabdomyosarcoma, relies upon the HMGA2IGF2BP2 pathway. Cancer Res 73:3041-3050.

Lyst MJ, Ekiert R, Ebert DH, Merusi C, Nowak J, Selfridge J, Guy J, Kastan NR, Robinson ND, de Lima Alves F, Rappsilber J, Greenberg ME, Bird A (2013) Rett syndrome mutations abolish the interaction of MeCP2 with the NCoR/SMRT co-repressor. Nat Neurosci 16:898-902.

Mellén M, Ayata P, Dewell S, Kriaucionis S, Heintz N (2012) MeCP2 binds to 5hmC enriched within active genes and accessible chromatin in the nervous system. Cell 151:1417-1430.

Meshorer E, Misteli T (2006) Chromatin in pluripotent embryonic stem cells and differentiation. Nat Rev Mol Cell Biol 7:540-546.

Meshorer E, Yellajoshula D, George E, Scambler PJ, Brown DT, Misteli T (2006) Hyperdynamic plasticity of chromatin proteins in pluripotent embryonic stem cells. Dev Cell 10:105-116.

Miller FD, Gauthier AS (2007) Timing is everything: making neurons versus glia in the developing cortex. Neuron 54:357-369.

Molofsky AV, Pardal R, Iwashita T, Park IK, Clarke MF, Morrison SJ (2003) Bmi-1 dependence distinguishes neural stem cell self-renewal from progenitor proliferation. Nature 425:962-967.

Molyneaux BJ, Arlotta P, Menezes JR, Macklis JD (2007) Neuronal subtype specification in the cerebral cortex. Nat Rev Neurosci 8:427-437.

Muotri AR, Chu VT, Marchetto MC, Deng W, Moran JV, Gage FH (2005) Somatic mosaicism in neuronal precursor cells mediated by L1 retrotransposition. Nature 435:903-910.

Muotri AR, Gage FH (2006) Generation of neuronal variability and complexity. Nature 441:1087-1093.

Muotri AR, Marchetto MC, Coufal NG, Oefner R, Yeo G, Nakashima K, Gage FH (2010) L1 retrotransposition in neurons is modulated by MeCP2. Nature 468:443-446.

Na ES, Monteggia LM (2011) The role of MeCP2 in CNS development and function. Horm Behav 59:364-368. 
Nagao M, Campbell K, Burns K, Kuan CY, Trumpp A, Nakafuku M (2008) Coordinated control of self-renewal and differentiation of neural stem cells by Myc and the p19ARF-p53 pathway. J Cell Biol 183:1243-1257.

Namihira M, Kohyama J, Semi K, Sanosaka T, Deneen B, Taga T, Nakashima K (2009) Committed neuronal precursors confer astrocytic potential on residual neural precursor cells. Dev Cell 16:245-255.

Namihira M, Nakashima K (2013) Mechanisms of astrocytogenesis in the mammalian brain. Curr Opin Neurobiol.

Nan X, Campoy FJ, Bird A (1997) MeCP2 is a transcriptional repressor with abundant binding sites in genomic chromatin. Cell 88:471-481.

Newman MA, Thomson JM, Hammond SM (2008) Lin-28 interaction with the Let-7 precursor loop mediates regulated microRNA processing. RNA 14:1539-1549.

Nishino J, Kim I, Chada K, Morrison SJ (2008) Hmga2 promotes neural stem cell selfrenewal in young but not old mice by reducing p16Ink4a and p19Arf Expression. Cell 135:227-239.

Oguro H, Yuan J, Tanaka S, Miyagi S, Mochizuki-Kashio M, Ichikawa H, Yamazaki S, Koseki H, Nakauchi H, Iwama A (2012) Lethal myelofibrosis induced by Bmi1-deficient hematopoietic cells unveils a tumor suppressor function of the polycomb group genes. J Exp Med 209:445-454.

Onoguchi M, Hirabayashi Y, Koseki H, Gotoh Y (2012) A noncoding RNA regulates the neurogenin1 gene locus during mouse neocortical development. Proc Natl Acad Sci U S A 109:16939-16944.

Pearson EC, Bates DL, Prospero TD, Thomas JO (1984) Neuronal nuclei and glial nuclei from mammalian cerebral cortex. Nucleosome repeat lengths, DNA contents and H1 contents. Eur J Biochem 144:353-360.

Pereira JD, Sansom SN, Smith J, Dobenecker MW, Tarakhovsky A, Livesey FJ (2010) Ezh2, the histone methyltransferase of PRC2, regulates the balance between selfrenewal and differentiation in the cerebral cortex. Proc Natl Acad Sci U S A 107:15957-15962.

Piskounova E, Viswanathan SR, Janas M, LaPierre RJ, Daley GQ, Sliz P, Gregory RI (2008) Determinants of microRNA processing inhibition by the developmentally regulated RNA-binding protein Lin28. J Biol Chem 283:21310-21314.

Reeves R (2001) Molecular biology of HMGA proteins: hubs of nuclear function. Gene 277:63-81.

Reeves R (2010) Nuclear functions of the HMG proteins. Biochim Biophys Acta 1799:314.

Rudenko A, Dawlaty MM, Seo J, Cheng AW, Meng J, Le T, Faull KF, Jaenisch R, Tsai LH (2013) Tet1 is critical for neuronal activity-regulated gene expression and memory extinction. Neuron 79:1109-1122.

Rybak A, Fuchs H, Smirnova L, Brandt C, Pohl EE, Nitsch R, Wulczyn FG (2008) A feedback loop comprising lin-28 and let-7 controls pre-let-7 maturation during neural stem-cell commitment. Nat Cell Biol 10:987-993.

Sanosaka T, Namihira M, Asano H, Kohyama J, Aisaki K, Igarashi K, Kanno J, Nakashima K (2008) Identification of genes that restrict astrocyte differentiation of midgestational neural precursor cells. Neuroscience 155:780-788.

Schwartz YB, Pirrotta V (2007) Polycomb silencing mechanisms and the management of genomic programmes. Nat Rev Genet 8:9-22. 
Shah SN, Kerr C, Cope L, Zambidis E, Liu C, Hillion J, Belton A, Huso DL, Resar LM (2012) HMGA1 reprograms somatic cells into pluripotent stem cells by inducing stem cell transcriptional networks. PLoS One 7:e48533.

Shen Q Wang Y, Dimos JT, Fasano CA, Phoenix TN, Lemischka IR, Ivanova NB, Stifani S, Morrisey EE, Temple S (2006) The timing of cortical neurogenesis is encoded within lineages of individual progenitor cells. Nat Neurosci 9:743-751.

Shoemaker LD, Arlotta P (2010) Untangling the cortex: Advances in understanding specification and differentiation of corticospinal motor neurons. Bioessays 32:197-206.

Skene PJ, Illingworth RS, Webb S, Kerr AR, James KD, Turner DJ, Andrews R, Bird AP (2010) Neuronal MeCP2 is expressed at near histone-octamer levels and globally alters the chromatin state. Mol Cell 37:457-468.

Spruijt CG, Gnerlich F, Smits AH, Pfaffeneder T, Jansen PW, Bauer C, Münzel M, Wagner M, Müller M, Khan F, Eberl HC, Mensinga A, Brinkman AB, Lephikov K, Müller U, Walter J, Boelens R, van Ingen H, Leonhardt H, Carell T, Vermeulen M (2013) Dynamic readers for 5-(hydroxy)methylcytosine and its oxidized derivatives. Cell 152:1146-1159.

Szulwach KE, Li X, Li Y, Song CX, Wu H, Dai Q Irier H, Upadhyay AK, Gearing M, Levey AI, Vasanthakumar A, Godley LA, Chang Q, Cheng X, He C, Jin P (2011) 5-hmCmediated epigenetic dynamics during postnatal neurodevelopment and aging. Nat Neurosci 14:1607-1616.

Takahashi K, Tanabe K, Ohnuki M, Narita M, Ichisaka T, Tomoda K, Yamanaka S (2007) Induction of pluripotent stem cells from adult human fibroblasts by defined factors. Cell 131:861-872.

Takahashi K, Yamanaka S (2006) Induction of pluripotent stem cells from mouse embryonic and adult fibroblast cultures by defined factors. Cell 126:663-676.

Takahashi T, Goto T, Miyama S, Nowakowski RS, Caviness VS (1999) Sequence of neuron origin and neocortical laminar fate: relation to cell cycle of origin in the developing murine cerebral wall. J Neurosci 19:10357-10371.

Takizawa T, Nakashima K, Namihira M, Ochiai W, Uemura A, Yanagisawa M, Fujita N, Nakao M, Taga T (2001) DNA methylation is a critical cell-intrinsic determinant of astrocyte differentiation in the fetal brain. Dev Cell 1:749-758.

Viswanathan SR, Daley GQ, Gregory RI (2008) Selective blockade of microRNA processing by Lin28. Science 320:97-100.

Wood LJ, Mukherjee M, Dolde CE, Xu Y, Maher JF, Bunton TE, Williams JB, Resar LM (2000) HMG-I/Y, a new c-Myc target gene and potential oncogene. Mol Cell Biol 20:5490-5502.

Wu H, D'Alessio AC, Ito S, Xia K, Wang Z, Cui K, Zhao K, Sun YE, Zhang Y (2011) Dual functions of Tet 1 in transcriptional regulation in mouse embryonic stem cells. Nature 473:389-393.

Yu YC, Bultje RS, Wang X, Shi SH (2009) Specific synapses develop preferentially among sister excitatory neurons in the neocortex. Nature 458:501-504.

Zhang F, Cong L, Lodato S, Kosuri S, Church GM, Arlotta P (2011) Efficient construction of sequence-specific TAL effectors for modulating mammalian transcription. Nat Biotechnol 29:149-153.

Zhou Z, Hong EJ, Cohen S, Zhao WN, Ho HY, Schmidt L, Chen WG, Lin Y, Savner E, Griffith EC, Hu L, Steen JA, Weitz CJ, Greenberg ME (2006) Brain-specific phosphorylation of MeCP2 regulates activity-dependent Bdnf transcription, dendritic growth, and spine maturation. Neuron 52:255-269. 


\section{Figure legend}

\section{Figure 1. Neuronal development}

NPCs first sequentially produce the various types of neurons in the neurogenic phase and then produce astrocytes in the astrogenic phase. When NPCs produce a neuron, the cell first undergoes neuronal fate commitment and then later acquires its unique features, such as axons, dendrites, synapses, and polarized membrane potential.

Figure 2. HMGA proteins contribute to neurogenic potential in early-stage NPCs.

(A) In the early stage, positive feedback between HMGA and Myc regulates the neurogenic potential of NPCs. At the transition from the neurongenic to astrogenic phase, repression of HMGA by the PcG complex may play a role in suppressing the neurogenic potential.

(B) Early-stage NPCs have a globally open chromatin state, and it becomes condensed during neocortical development. Establishing such an open chromatin state is one way that HMGA proteins regulate the neurogenic potential. A similar correlation between open chromatin and differentiation potential is seen in ES cells.

\section{Figure 3. Increase of $5 \mathrm{hmC}$ and $\mathrm{MeCP} 2$ play a role in neuronal differentiation.}

(A) During neuronal differentiation, Tet 2 and Tet 3 convert $5 \mathrm{mC}$ into $5 \mathrm{hmC}$ and the total level of $5 \mathrm{hmC}$ increases.

(B) Upregulation of $\mathrm{MeCP} 2$ in late neuronal development results in the replacement of histone $\mathrm{H} 1$ by $\mathrm{MeCP} 2$. Because MeCP2 recruits HDACs, this increase in MeCP2 reduces the global acetylation level.

(C) Various stimuli, such as membrane depolarization and BDNF, induce the phosphorylation of $\mathrm{MeCP} 2$. It is possible that when $\mathrm{MeCP} 2$ is phosphorylated, it is removed from target gene loci, thus affecting gene expression as well as morphological and functional changes.

However, recent studies support a model in which $\mathrm{MeCP} 2$ remains bound to the genome even upon phosphorylation. Related to this model, it was recently found that T308 phosphorylation disrupts MeCP2's interaction with the NCoR repressor, thus suggesting a mechanism by which phosphorylation of MeCP2 might alter gene expression while MeCP2 remains bound to the genome. 
Fig. 1

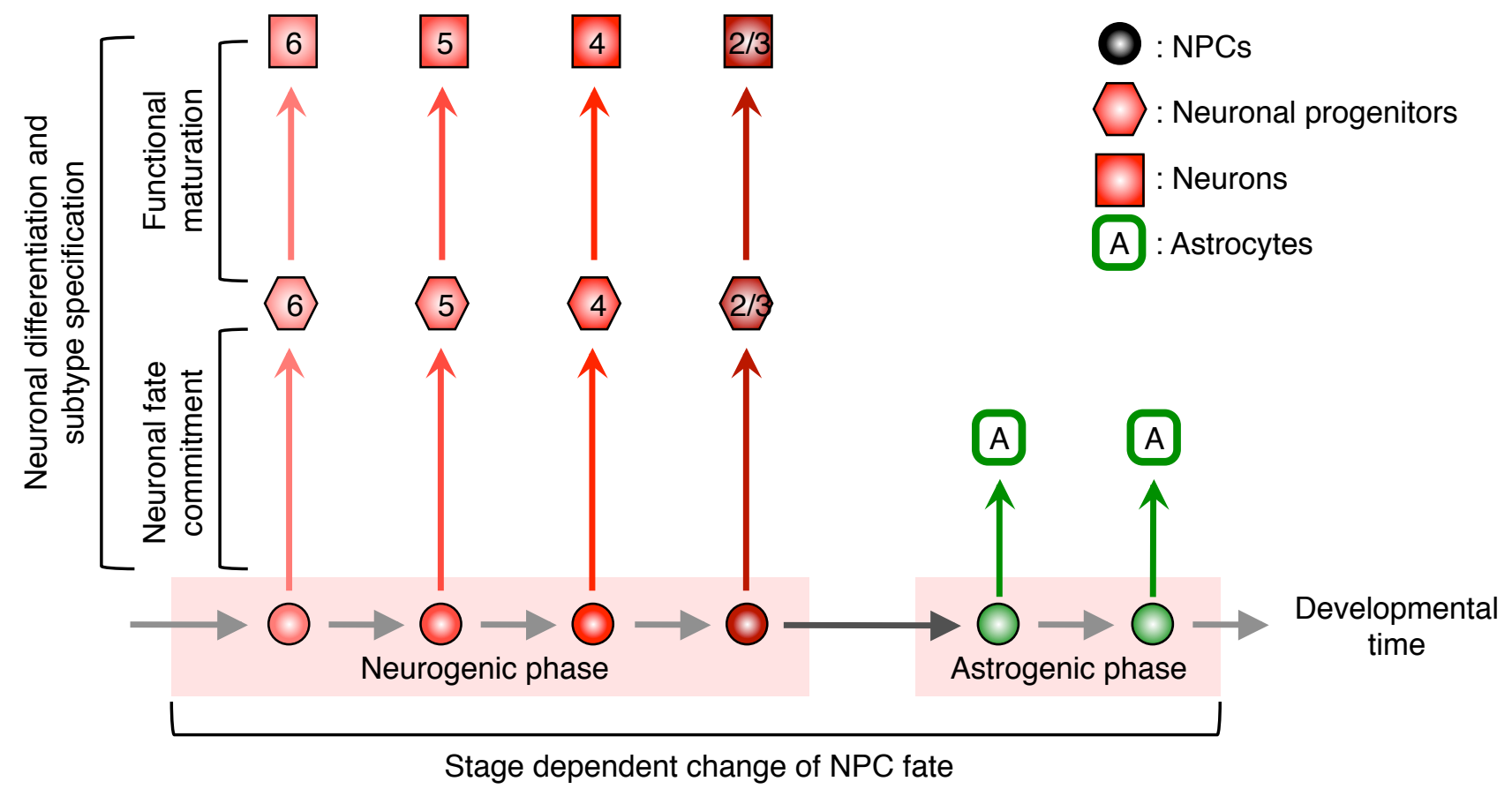


Fig. 2

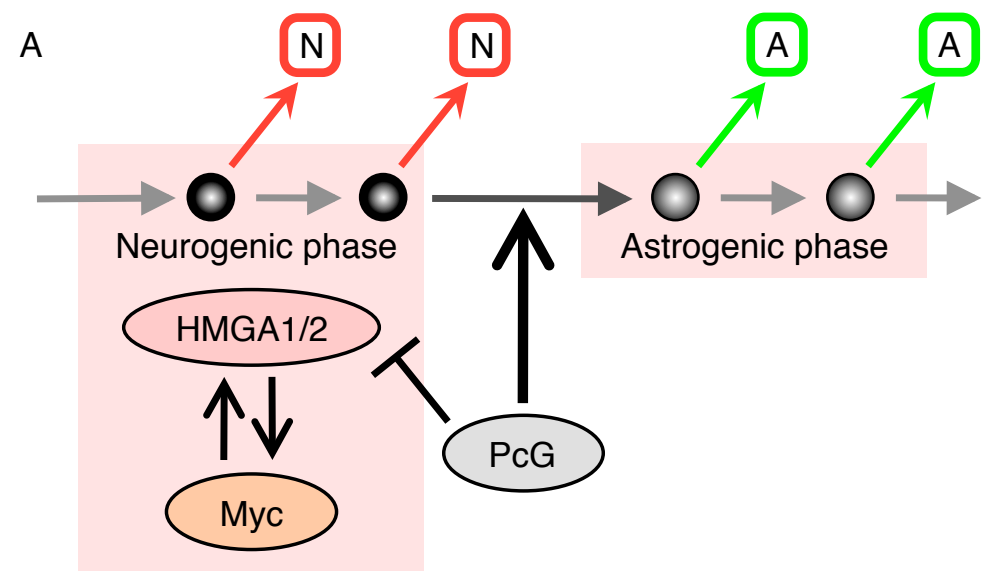

Developmental time

$\boldsymbol{O}$ : NPCs

N : Neurons

A : Astrocytes

B
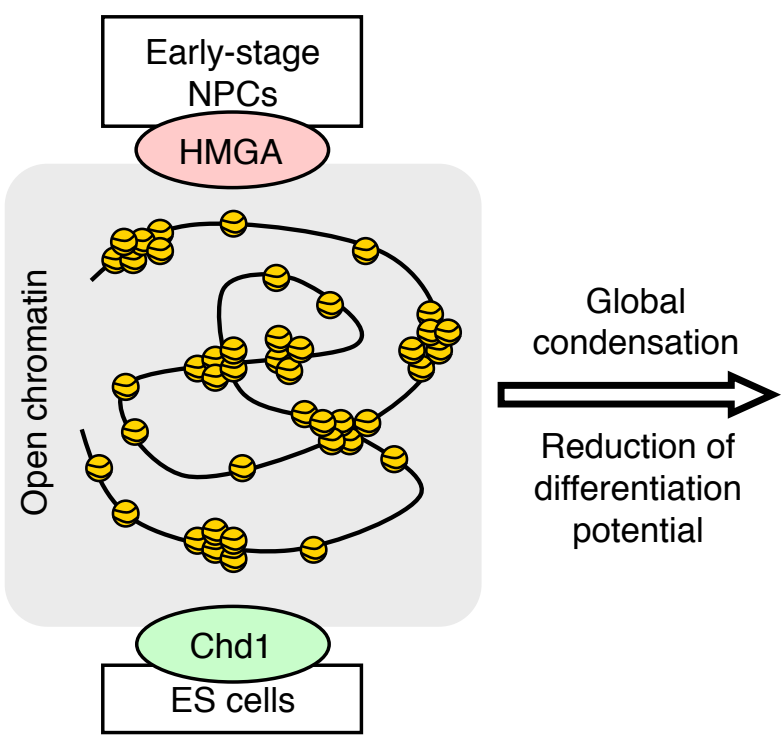

Reduction of differentiation potential

Late-stage NPCs

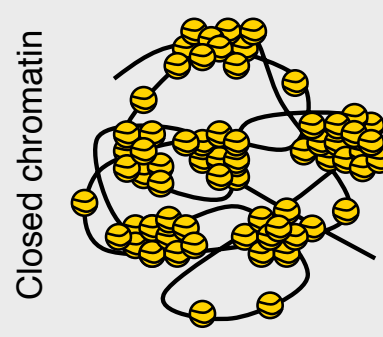

Lineage-committed cells 
Fig. 3

A
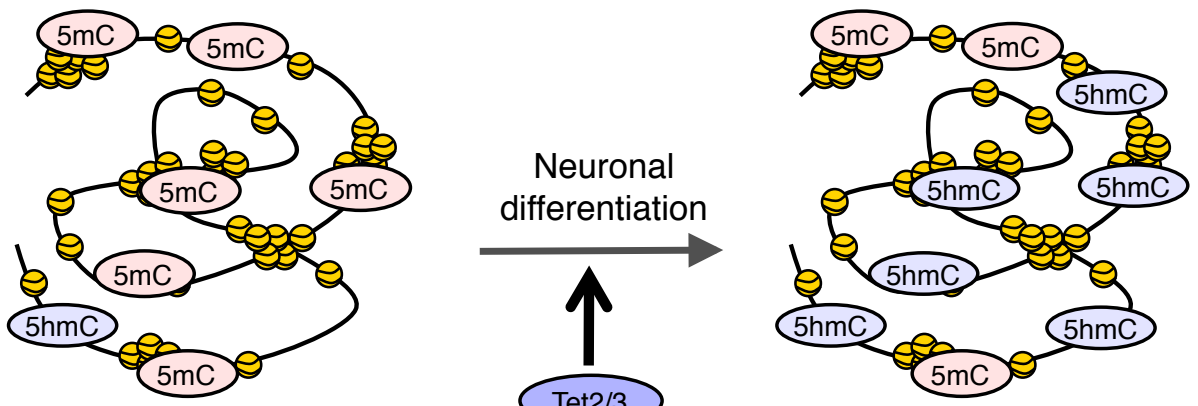

B
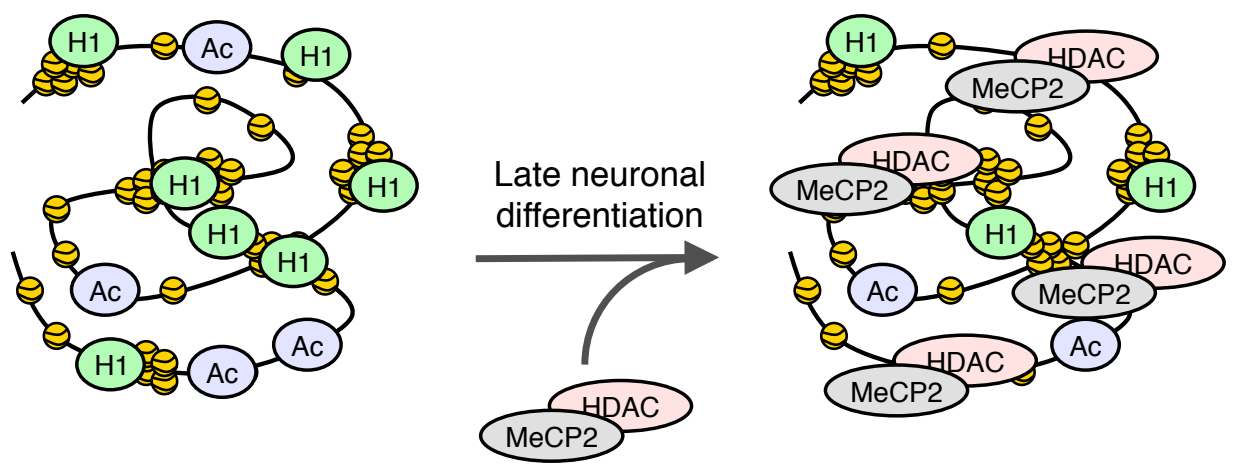

C

MeCP2 target genes
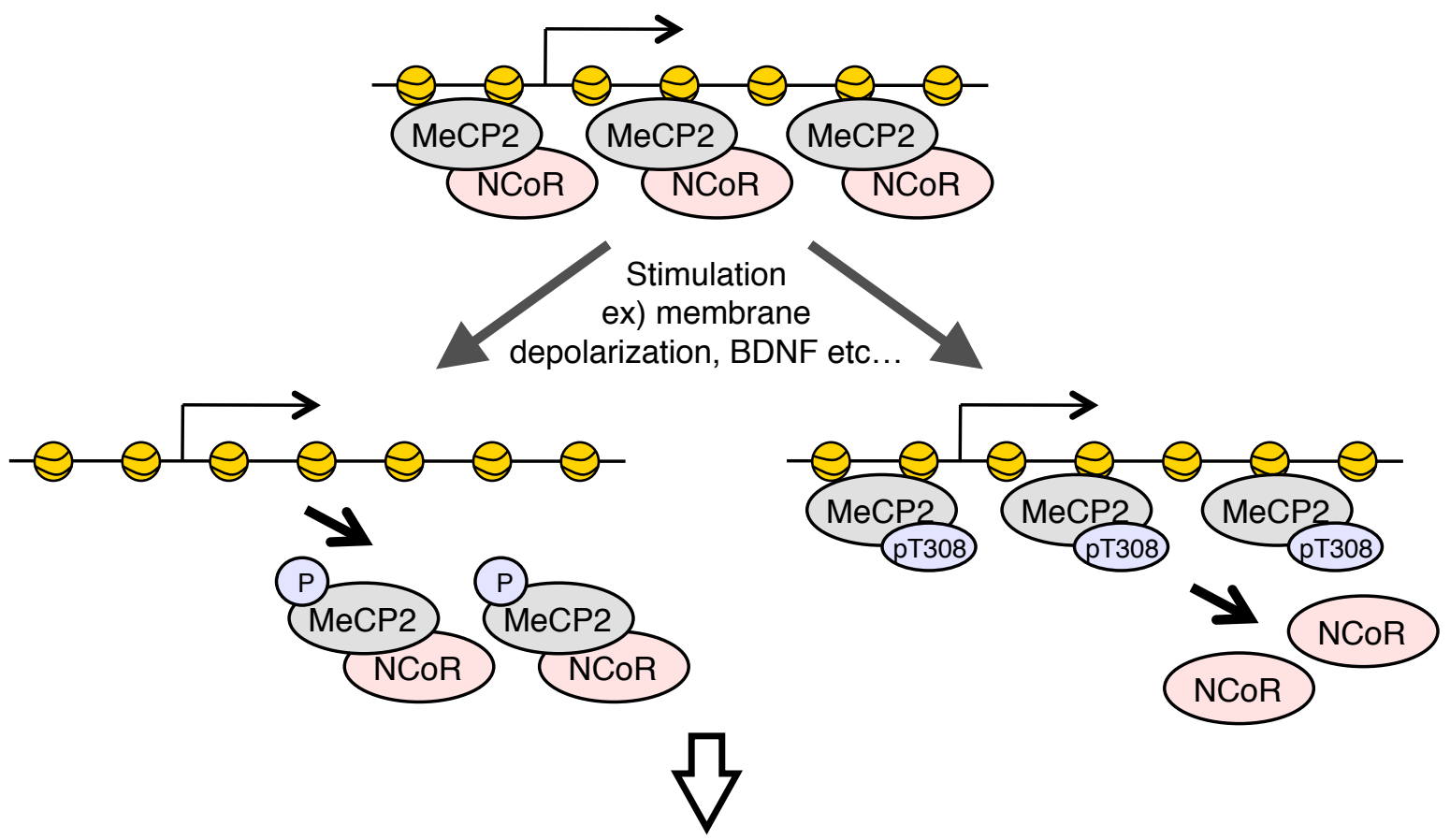

Alteration in gene expression and in synapse and dendrite development 